\title{
Can Geopolymer Materials Be Optimized for Sustainable Building Envelope Applications? A Preliminary Development and Characterization Study ${ }^{\dagger}$
}

\author{
Gloria Pignatta $1,2, *\left(\mathbb{D}\right.$, Vincent Wong ${ }^{3}$, Pramod Koshy ${ }^{3}\left[\right.$ and Charles Christopher Sorrell ${ }^{2,3}$ \\ 1 School of Built Environment, Faculty of Arts, Design, and Architecture, University of New South \\ Wales (UNSW), Sydney, NSW 2052, Australia \\ 2 Material and Manufacturing Future Institute (MMFI), University of New South Wales (UNSW), \\ Sydney, NSW 2052, Australia; c.sorrell@unsw.edu.au \\ 3 School of Materials Science and Engineering, Faculty of Science, University of New South Wales (UNSW), \\ Sydney, NSW 2052, Australia; v.d.wong@unsw.edu.au (V.W.); koshy@unsw.edu.au (P.K.) \\ * Correspondence: g.pignatta@unsw.edu.au \\ + Presented at the 3rd Built Environment Research Forum, Sydney, Australia, 1 December 2021.
}

Citation: Pignatta, G.; Wong, V.; Koshy, P.; Sorrell, C.C. Can Geopolymer Materials Be Optimized for Sustainable Building Envelope Applications? A Preliminary Development and Characterization Study. Environ. Sci. Proc. 2021, 12, 11. https://doi.org/10.3390/ environsciproc2021012011

Academic Editor: Khan

Rahmat Ullah

Published: 17 February 2022

Publisher's Note: MDPI stays neutral with regard to jurisdictional claims in published maps and institutional affiliations.

Copyright: (C) 2022 by the authors. Licensee MDPI, Basel, Switzerland. This article is an open access article distributed under the terms and conditions of the Creative Commons Attribution (CC BY) license (https:// creativecommons.org/licenses/by/ $4.0 /)$.

\begin{abstract}
The materials used in the construction industry have a fundamental role in the development and achievement of low-carbon structures. This research aims to develop and characterize innovative and affordable renewable materials that can meet these low carbon requirements for building envelopes and internal element applications. These materials are geopolymers, which are being researched for fire-resistance, nuclear storage, and cement-based structural applications. Geopolymers are commonly fabricated from high-volume waste materials (e.g., fly ash and blast furnace slag) that are stored in landfill and tailings ponds and have the capacity to facilitate the transition toward a more sustainable and energy-efficient built environment while contributing to the circular economy in the building sector. Two geopolymers, a reference and a prototype, were fabricated and characterized in-lab for their thermal and optical properties to assess their performance for use as building envelope materials. Preliminary results suggest that the prototype has potential for use in green, lightweight building applications. Further optimization of the geopolymers' thermal and optical performances will open new opportunities for the use of this material in buildings.
\end{abstract}

Keywords: building energy efficiency; thermal comfort; decarbonization; thermal insulation; cenospheres; thermal conductivity; solar reflectance; thermal emittance

\section{Introduction}

The building industry is a key contributor to climate change, responsible for about one third of total $\mathrm{CO}_{2}$ emissions as well as substantial amounts of material and energy consumption [1]. Thus, decarbonizing the built environment is a challenging task that requires innovation and major changes from what is considered business-as-usual in terms of common practices in the building and construction sector. Research and development on innovative, sustainable, and affordable building materials are essential to enhance the total building performance (e.g., including thermal, energy, optical, and acoustic performances) and reduce the environmental impact of the building sector.

Geopolymers (i.e., inorganic polymers) have been investigated for use in the building sector for lowering costs and improving environmental sustainability because geopolymer concrete is considered a valid alternative to ordinary Portland cement concrete. The compositions use fly ash deriving from thermal power plants, among other by-products or waste materials, which diverts these materials from landfill and storage, thereby reducing $\mathrm{CO}_{2}$ emissions, and obtaining a durable fireproof environmentally-friendly concrete [2] Geopolymer cement technology [3], based on the geopolymerization of aluminosilicates 
(e.g., fly ash and blast furnace slag), is being developed and it is not widely adopted yet in the building sector mainly due to market barriers, limited industry engagement [4], and lack of standards. Current geopolymer applications for the built environment can be grouped in two categories, resins and binders (e.g., thermal insulation components, fire-resistant materials, foams, low-energy ceramic tiles, refractory materials, paints, and grouts), and cement and concretes (e.g., clay bricks, and low carbon cement and concrete elements).

This study aims to establish a new paradigm for geopolymer applications through the innovative tailoring of these materials. In the building sector, the availability of renewable and affordable light-weight building components made of geopolymers can improve the thermal-energy efficiency of buildings, both new and old. This would assist in reducing the annual energy bill, lowering the environmental impact, and improving the indoor acoustic and thermal comfort, particularly in social housing where vulnerable people suffer from energy poverty and heat-related health problems that are exacerbated by the increased frequency of extreme weather events (i.e., heatwaves). In the context of the recent COVID19 pandemic, where working or isolating at home is increasing globally, the need for energy conservation measures in residential buildings has become essential especially considering the rising energy prices and the effect of climate change on increased demand on cooling requirements.

Based on prior experience in geopolymer design and applications [5] and sustainable and high performing materials for the building envelope [6,7], new building components comprised of different geopolymer mixes have been produced and investigated. The developed reference fly ash-based geopolymer is very strong, cheap, renewable, extremely easy to use, and shows rapid strength development. These require lower water content compared to the traditional Portland cement while demonstrating higher temperature stability (<600 $\left.{ }^{\circ} \mathrm{C}-800{ }^{\circ} \mathrm{C}\right)$, higher compressive strength (50-80 MPa), and lower leachability [4]. By further increasing the porosity, the thermal and acoustic insulation can be enhanced with some compromise of the mechanical strength. The first prototype was developed by increasing the extent of porosity with respect to the reference geopolymer cured at room temperature and the relevant data is presented here along with data on its thermal and optical properties. Both the reference and the prototype materials have already been tested for their mechanical strengths [8] and can be used for producing building components (e.g., roof panels, roof tiles, and claddings) for internal and external applications.

\section{Materials and Methods}

A reference geopolymer mix (G-FA) and the respective samples for the in-lab characterization were prepared starting from a geopolymer composition (Figure 1). The composition consisted of: (i) aluminosilicate raw materials derived from waste resources (e.g., fly ash and blast furnace slag); (ii) alkaline activators, such as alkali metal silicates $\left(\mathrm{Na}_{2} \mathrm{SiO}_{3}\right)$; (iii) sand; and (iv) water (proportions shown in Table 1). For this geopolymer composition, the waste materials undergo reactions with the alkaline activators leading to the geopolymer gel formation during the mixing and curing at room temperature [8].

Table 1. Geopolymer weight compositions expressed as component to binder ratio (binder weight $=1)$.

\begin{tabular}{|c|c|c|c|c|c|c|}
\hline \multirow[b]{2}{*}{ Material } & \multicolumn{3}{|c|}{ Binder } & \multirow[b]{2}{*}{$\mathrm{Na}_{2} \mathrm{SiO}_{3}$} & \multirow[b]{2}{*}{ Sand } & \multirow[b]{2}{*}{ Water } \\
\hline & $\begin{array}{c}\text { Fly Ash Class } \\
\text { F (FA) }\end{array}$ & $\begin{array}{l}\text { Cenospheres } \\
\text { (C) }\end{array}$ & $\begin{array}{l}\text { Ground Granulated Blast } \\
\text { Furnace Slag (GGBFS) }\end{array}$ & & & \\
\hline $\begin{array}{c}\text { G-FA (Fly ash-based } \\
\text { Geopolymer-reference) }\end{array}$ & 0.400 & - & 0.600 & 0.240 & 2.00 & 0.505 \\
\hline $\begin{array}{l}\text { G-C (Cenosphere-based } \\
\text { Geopolymer-prototype) }\end{array}$ & - & 0.400 & 0.600 & 0.240 & 2.00 & 0.505 \\
\hline
\end{tabular}




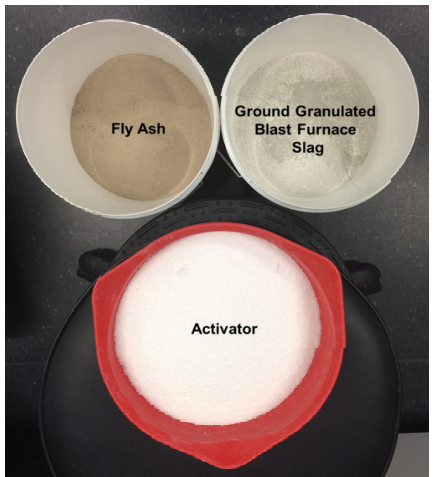

(a)

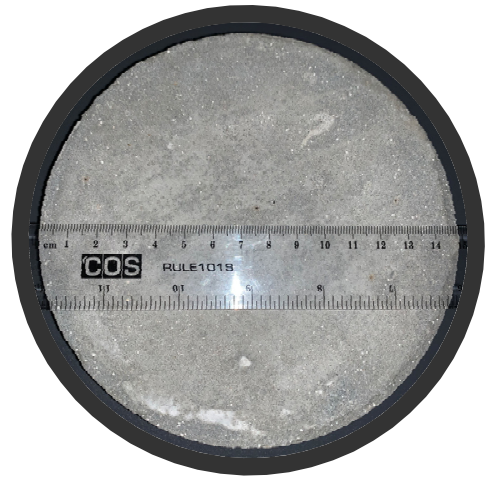

(b)

Figure 1. Geopolymer material: (a) binder and activator used for the production of the reference geopolymer material; and (b) produced reference sample.

The first investigated prototype is a cenosphere based geopolymer (G-C) which is characterized by lower bulk density and high apparent porosity compared to the G-FA. As reported in Table 1, their composition differs only in terms of the use of hollow cenospheres instead of the solid fly ash particles. It should be noted that cenospheres are also a by-product of the coal combustion process in power stations.

In this study, samples of specific dimensions of each geopolymer composition were tested for their thermal and optical performance at standard lab air temperature $\left(24^{\circ} \mathrm{C}\right)$ and relative humidity $(50 \pm 10 \%)$. The thermal characterization consisted of the measurement of the thermal conductivity, thermal diffusivity, and specific heat testing by means of the Hot Disk TPS1500 (Transient Plane Source Technique). The optical properties were characterized by means of a Lambda $1050 \mathrm{UV} /$ Vis/NIR spectrophotometer with the integrating sphere by PerkinElmer and the AE1 RD1 D\&D portable emissometer, according to the ASTM E930-12 and ASTM G173-03 for the solar reflectivity and the ASTM C1371-15 for the thermal emittance, respectively (Figure 2).

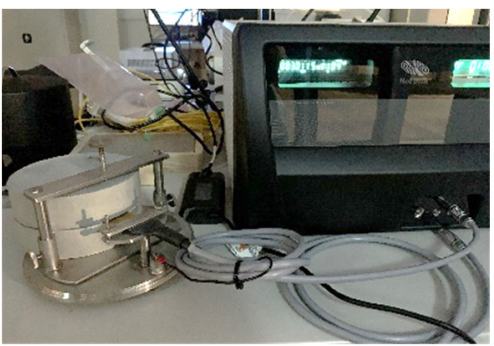

(a)

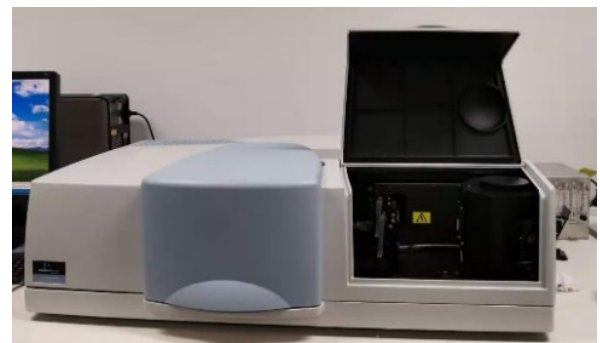

(b)

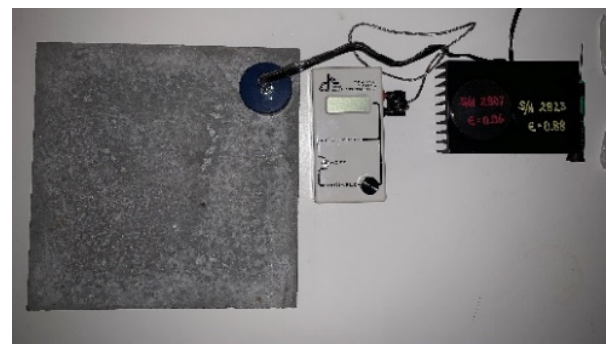

(c)

Figure 2. In-lab characterization: (a) Hot disk TPS1500 for thermal testing; (b) UV-Vis-NIR spectrophotometer with integrating spheres for solar reflectivity testing; and (c) AE1 RD1 D\&D portable emissometer for thermal emittance testing.

\section{Results}

Table 2 presents the thermal and optical data for the reference geopolymer (G-FAbulk density of $2096 \mathrm{~kg} / \mathrm{m}^{3}$ ) and the lightweight geopolymer prototype (G-C-bulk density of $1562 \mathrm{~kg} / \mathrm{m}^{3}$ ). Although G-C presents lower thermal conductivity compared with the reference G-FA (54\% decrease), it cannot be considered as a good insulation material owing to the value being higher than $0.1 \mathrm{~W} / \mathrm{mK}$ which is the upper limit considered for thermal insulation [9]. G-C also shows higher thermal diffusivity and lower specific heat compared to G-FA. On the other hand, G-FA and G-C present similar high values in terms of thermal emittance $(\sim 90 \%)$ and similar low values in terms of initial solar reflectance (23-25\%). While low values of solar reflectance can cause building overheating, high values 
of thermal emittance can help the building to emit the absorbed heat. Higher values of solar reflectance are recommended in hot climates (i.e., 75-90\%) when it is necessary to reduce indirect solar gain in the building and mitigate the urban heat island effect.

Table 2. Thermal and optical properties of the investigated geopolymer materials.

\begin{tabular}{cccccc}
\hline Material & $\begin{array}{c}\text { Thermal } \\
\text { Conductivity [W/mK] }\end{array}$ & $\begin{array}{c}\text { Thermal Diffusivity } \\
{\left[\mathbf{m m}^{2} / \mathbf{s}\right]}\end{array}$ & $\begin{array}{c}\text { Specific Heat } \\
{\left[\mathbf{M} / \mathbf{m}^{2} \mathbf{K}\right]}\end{array}$ & $\begin{array}{c}\text { Thermal } \\
\text { Emissivity [-] }\end{array}$ & $\begin{array}{c}\text { Solar } \\
\text { Reflectance [-] }\end{array}$ \\
\hline G-FA (reference) & 1.863 & 0.913 & 2.039 & 0.89 & 0.23 \\
G-C (prototype) & 0.858 & 1.023 & 0.839 & 0.90 & 0.25 \\
\hline
\end{tabular}

\section{Conclusions}

In response to the urgent requirement for building and construction sector to adapt to growing environmental regulations aimed at addressing global warming, there is a growing need for novel binding materials with low carbon emissions in order to replace the carbon-intensive cement in concrete. The present work aims to support the building materials industry with the introduction of an innovative, sustainable, and affordable geopolymer material with improved thermal-energy performance for installation in the building envelope (for internal and external applications). The enhanced use of these materials will enhance the circular economy score of the industry by enhancing waste material use and diverting materials from landfill and storage.

The first geopolymer prototype (G-C) based on hollow cenospheres was developed, characterized, and compared to the reference fly ash-based geopolymer (G-FA) in terms of thermal and optical properites. The preliminary data shows that this composition has potential for green, lightweight building applications. Further optimization of the mix design is required to modify the thermal and optical properties.

In future developments, the thermal energy storage capacity of the novel building component will be optimized by including phase change materials to the geopolymer mix.

Author Contributions: Conceptualization: G.P., P.K., and C.C.S.; methodology: G.P., P.K., and C.C.S.; formal analysis: G.P.; investigation: G.P.; data curation: G.P.; writing-original draft preparation: G.P.; writing—review and editing: G.P., V.W., P.K., and C.C.S.; visualization: G.P.; supervision: G.P., P.K., and C.C.S. All authors have read and agreed to the published version of the manuscript.

Funding: This research was funded by the Material and Manufacturing Future Institute (MMFI), 2020 MMFI Seed Grant.

Acknowledgments: The authors would like to thank the UNSW Material and Manufacturing Future Institute and the UNSW School of Materials Science and Engineering for subsidized use of their laboratory facilities. A special thanks go to the UNSW research personnel Uttam Mittal and Jie Feng and Yu Zhang for assisting with material development and in-lab tests.

Conflicts of Interest: The authors declare no conflict of interest.

\section{References}

1. 6th Intergovernmental Panel on Climate Change (IPCC) Assessment Report; 2021 Sixth Assessment Report; IPCC: Geneva, Switzerland, 2021.

2. Singh, N.B. Fly Ash-Based Geopolymer Binder: A Future Construction Material. Minerals 2018, 8, 299. [CrossRef]

3. Norton, M.G.; Provis, J.L. 1000 at 1000: Geopolymer Technology-The Current State of the Art. J. Mater. Sci. 2020, 55, 13487-13489. [CrossRef]

4. van Deventer, J.S.J.; Provis, J.L.; Duxson, P. Technical and Commercial Progress in the Adoption of Geopolymer Cement. Miner. Eng. 2012, 29, 89-104. [CrossRef]

5. Yeoh, M.L.Y.; Ukritnukun, S.; Rawal, A.; Davies, J.; Kang, B.J.; Burrough, K.; Aly, Z.; Dayal, P.; Vance, E.R.; Gregg, D.J.; et al. Mechanistic impacts of long-term gamma irradiation on physicochemical, structural, and mechanical stabilities of radiationresponsive geopolymer pastes. J. Hazard. Mater. 2021, 407, 124805. [CrossRef] [PubMed]

6. Castaldo, V.L.; Coccia, V.; Cotana, F.; Pignatta, G.; Pisello, A.L.; Rossi, F. Thermal-Energy Analysis of Natural “Cool” Stone Aggregates as Passive Cooling and Global Warming Mitigation Technique. Urban Clim. 2015, 14, 301-314. [CrossRef] 
7. Pisello, A.L.; Castaldo, V.L.; Pignatta, G.; Cotana, F.; Santamouris, M. Experimental In-Lab and In-Field Analysis of Waterproof Membranes for Cool Roof Application and Urban Heat Island Mitigation. Energy Build. 2016, 114, 180-190. [CrossRef]

8. Tang, W.X.; Pignatta, G.; Sepasgozar, S.M. Life-Cycle Assessment of Fly Ash and Cenosphere-Based Geopolymer Material. Sustainability 2021, 13, 11167. [CrossRef]

9. Anh, L.D.H.; Pasztory, Z. An Overview of Factors Influencing Thermal Conductivity of Building Insulation Materials. J. Build. Eng. 2021, 44, 102604. [CrossRef] 